\title{
The Protection Measures of Patient Privacy
}

\author{
Na Wang \\ Department of Anesthesiology \\ The First Hospital of Jilin University \\ Changchun, China \\ wangna080613@163.com
}

\author{
Jinguo Wang* (corresponding author) \\ Department of Urology \\ The First Hospital of Jilin University \\ Changchun, China \\ wangjinguolily@163.com
}

\begin{abstract}
To investigate how much medical personnel and patients know about the patients' privacy protection and to explore protective measures. To analyze the present status of privacy protection and the hospitals questionnaire surveys which were conducted on patients and medical workers in several hospitals. Most patients take personal privacy very seriously, especially for the exposure of the body private parts. They have shy feeling and hope physical sensitive part covered before and after the operation and examination. Some medical personnel admit that they discuss patients in public, privately talk about patient privacy, leak privacy information because of loss of medical records. The legal consciousness and professional ethics of medical personnel should be improved. It is important measures to protect the patient's privacy to attach great importance to the protection of privacy parts of the body on the patients, and properly keep patients personal data private and maintain patients' privacy requirements.
\end{abstract}

Keywords-Patient privacy protection, law, doctor

\section{INTRODUCTION}

In the modern society, personality is regarded as the highest value, respect for human rights as the basic concept and goal of modern human rights movement. Patients' right of privacy is a reflection of patient dignity as human beings. Patients as a special social group are easier than general privacy to enjoy privacy violations. The professionalism of the medical technology and implementation determines the characteristics of medical behavior have to visit and contact patients privacy, the health care industry has always been a sensitive area of privacy infringement. Patients' right of privacy as an independent personality right, as well as other personality right should be protected by law. However, in real life, appear extremely vulnerable patients' right of privacy, in the hospital is the violation of patients' right of privacy. Patient privacy and doctors often exist between right and other rights such as the public's right to know the phenomenon of conflict, face the problem of rights conflict, how to protect the patient's privacy and other rights become a difficult problem to be solved. Research of patients' right of privacy protection to reduce the occurrence of medical dispute, is conducive to building a harmonious doctor-patient relationship, also is the important way of building a harmonious socialist society [1]. This paper USES semantic analysis, historical analysis, case analysis, value analysis and literature research methods to explore the patient privacy issues.

\section{Patient PRivacy Protection}

The interests of the right is legal form, the essence of right conflicts is right behind the hidden conflict between the interests of the. On the analysis of the theory of rights conflict and the principle of benefit measure, the patients' privacy and other rights conflict and its right to limit can use the theory to solve specific problems.

\section{A. The concept of patients' privacy}

The concept of right to know the earliest by the American journalist Kent cooper in the 1940s. Right to know is a natural person requires understanding, you should know that require especially society politics more openness and transparency, to satisfy the needs of its political and cultural life, with enthusiasm and openness. Privacy is a natural person to protect their privacy, not willing to your personal information and other private affairs is known by others, with negativity and privacy. Therefore, privacy and the right to know has always been a pair of opposing law category [2].

Patient privacy and doctors' right to know. Activity in diagnosis and treatment, the patients right to privacy and prescriptions of right conflict relationship is the typical embodiment of modern social rights conflict phenomenon, is also an important manifestation of the doctor-patient relationship conflict. Prescriptions right shows that the doctor has the right to know in the process of diagnosis and treatment patients and the related situation of the disease. Professional medical activities as much as possible the medical staff is always need to obtain information about the patient's disease, so that more accurate diagnosis and effective treatment of disease. Medical staffs who are in the process of diagnosis and treatment check body of patient inquired about their history, and so on and so forth will involve the patient's privacy. Both at the same time, each patient' information, hope the doctor can fully grasp their disease early cure disease, relieve pain, and want to minimize their privacy exposure. Therefore, on the one hand, people require medical staff to maximize benefits of the right to privacy on the other hand people want to give up less privacy to get the full of life and health. Strictly speaking, health providers' right to know is not a real "right to know", its itself does not bring interests to medical staff, as the custody of exercise can't bring benefit as guardians [3]. Activity is the performance of the duties of diagnosis and treatment of the medical staff of the behavior, exercise prescriptions' right to know is more of a legal duty. 


\section{B. The current status of patient's privacy}

Medical staff asks some diseases in patients with information are a prerequisite for correct diagnosis and treatment for patients, it is good for patients, and the medical staff is not the right to choose for or not. However, medical personnel to patients with the diagnosis and treatment of disease depend on the patient's privacy information. Patients must disclose information related to the disease state to the medical staff, if the patient to protect the patients right to privacy and not to disclose his own any privacy, medical staff even better then cannot accurate diagnosis and treatment. But prescriptions of right to know and shall not be liable is too large, the exercise of the right to know should is limited to the needs of the treatment of patients with disease. To be specific, limited scope of privacy disclosure. Patient privacy disclosure is limited to cure diseases related parts, information has nothing to do with the disease treatment, patients have the right to refused to disclose, patients with health providers also have the right to request, otherwise, it violated the patients right to privacy [4]. Aware of the limited medical staff of patient privacy. Only have a direct connection with the treatment of patients with disease medical staff didn't have the right to privacy of patients, according to any other person, has the right to the patients' privacy, unless express consent of patients.

The privacy of patients using limited way. Prescriptions in the diagnosis and treatment for patients in the process of privacy must be kept confidential and shall not be any leakage, preach to others. For the needs of medical scientific research using the patients' privacy they use a pseudonym or special handling of related images. All in all, solve the patients' right to privacy and prescriptions of right conflict shall apply the principle of necessity. Patient privacy and the public's right to know should follow the principle of legal reserve first, give way to the public's right to know, this is the relationship between personal interests and social public interests. Personal interests and social public interests has both the relativity and consistency. On the one hand, the interests of the individual are relative to the social and public interests, a certain amount of conflict with public interests. Everyone as individuals pursuing their own interests, and each person's pursuit of personal interests are often different, resulting in the conflict between personal interests and the interests of others as well as the conflict between personal interests and social public interests. On the other hand, personal interests and social public interests also have the characteristics of consistency. Society is made up of individuals; the individual is a part of society. Personal interest is the basic starting point and final home to return to the social and public interests, public interests and personal interests is one aspect. From local and short term view, social public interests and personal interests conflict there may be temporary, but no fundamental conflict, otherwise will inevitably negated for personal gain and abandoned. The concept of social and public interests exist a certain amount of controversy, definition of its scope also has the certain difficulty, but the real social and public interests is a common thing [5].

Social and public interests is a common set of long-term interests of the individual, rather than the above personal interests of the monster, so has certain priorities. However, compared with the patients right to privacy, although the public's right to know has certain priority validity, but not any expand the scope of use, must be in the specified in the limit of law, otherwise, will become the public's right to know some people seek personal gain than any excuse for personal privacy rights. Second, the public's right brings certain restrictions of patients' right of privacy, and shall follow the principle of proportion in their application. Patients' privacy as the embodiment of the interests of the individuals is extremely important for patients, at the expense of patients right to privacy may bring patients with sad, resentment, shame, etc. in agony. If personal opinion of human freedom degree of the desire to be squeezed beyond the required to protect the interests of other social reasonable compromise the limits of the consequences is very serious. Reductions of patients' right of privacy shall be made in the implementation of the public's right to know or maintenance, and should use a more moderate way limit, to maximize the protection of patients right to privacy.

\section{Protection methods}

In general, the patient's disease belongs to the category of the private sector, others have no right to know, but, in medical treatment activity when the patient's health may threaten to close contact with people's life and health, whether the third person shall enjoy the right to know? Based on the analysis of this kind of situation before, we'll look at some examples. An emergency doctor gave injuries patients for surgery, the patient was very clear. Surgery is very successful, but during the operation the doctor's fingers accidentally cut a little wound, also did not take the corresponding protective measures, and after the blood test results confirmed that the patients as having been infected with the HIV/AIDS. Due to patients is not informed, the doctor is likely to be infected with HIV/AIDS. At this point, although the patient's right to privacy is protected by the great, but it hurt close contact with the personnel's right to know, even the life and health. In this particular case, to save the patients' life physician may also be threatened by life at the same time, this is how unfair for physicians [6]. Reality is often accompanied by family members to the hospital diagnosis and treatment of patients with happens, doctors found that patients with a communicable disease may affect the persons who have close contact with, physicians have obligation to inform his family. Have happened at the same time, aim to the hospital for check-ups of the couples have told by the doctor of the female patients with abdomen "stretch marks" and lead to break up the final cause of medical dispute cases." The professional medical practitioners law" stipulated in article 22, physicians in the process of practicing shall protect the patient's privacy. Stipulated in article 12 of the law on the prevention and control of infectious diseases, disease prevention and control institutions and medical institutions shall not reveal that the relevant information, data privacy. Based on the provisions of the law, therefore, the medical staff learned that in the process of diagnosis and treatment of the patients' privacy shall not be disclosed to any third person, in the face of infectious diseases as well.

However, the protection of patients right of privacy and infringes upon the lawful rights and interests, to a third person 
should choose what kind of rights to give priority to protect? Is the first case is a coincidence, the legitimate interests of the patients privacy violations to a third person, and the third person is just to save his life when attending physician, therefore, the physician's right to know also harmed. Patient privacy and the right to life belongs to the patient's personality right, due to differences in individual cognition, everyone view of patients privacy and the right to life each weight, when the choice must be made, the choice of each person may also be different. But that's not going to discuss the contents of this paper, the above definition of rights conflict is a communicative activity between two or more than two rights conflict, rather than the same subject in the face of conflict of rights.

Patients right to privacy and the right to life is the patient's own the right subject, the patients to exercise the rights of their own and how to exercise the links often is determined by its own, especially the patients have the right conflict, especially according to the patient's will, because patients as a rational man benefit trade-off is one of the most say to oneself, under normal circumstances shall not interfere in others. In general, is the patient's right of life is more important than patients privacy, must choose often sacrifice some patients right of privacy to maintain the right to life. At this point, this article wants to discuss is in an emergency situation, when patients at risk life and consciousness has been lost or not fully awake, the patients privacy and the medical staff rescue their life how to coordinate conflict? In the process of the emergency medical treatment, the patients were in critical condition, seriously threatening the life of patients, medical staff to save patient life must in the urgent time to patients health care measures. According to statistics, in 4 minutes and 6 minutes after cardiac arrest began CPR, the success rate of recovery were $50 \%$ and $10 \%$ respectively, the differences between big that the medical staff must put all the energy used to rescue patients, and other circumstances it is difficult to scruple.

As a result, the tort liability law stipulated in article 60, patients have damage, because of the medical staff in rescuing critically ill patients such as emergency has obligations to exercise the reasonable diagnosis and treatment, the medical institution does not assume liability to pay compensation. In fact, in the case of emergency, requiring medical workers spend precious time and energy for how to treat patients with right of privacy and the right to life is difficult, sometimes don't consult. Therefore, in the process of emergency rescue, priority to maintain the patient's right to life, restrict patients right to privacy is the most professional ethics of medical staff in to heal the wounded and rescue the dying under the guidance of it shall make a choice, at the same time, this choice is consistent with human nature.

Perfect medical institution management system is an intrinsic factor to the healthy development of the hospital and maintains normal medical order. It can not only from the macroscopic Angle guide hospital operations, but also the specific link of supervision and the hospital from the microscopic view. Therefore, the quality of medical institutions shall improve the hospital managers, establish scientific and rigorous medical management system, realize the scientific and standardization of hospital management. On the internal working system of the medical institution shall specify a respect for patients right of privacy, and implement the specific work of medical personnel management and constraints, so it can in strict accordance with the technical procedures to implement medical behavior, from system on privacy and use of diagnosis and treatment in patients with normal intervention act of infringement of privacy to make a clear distinction. In medical records management, strict management of patient records and test results of medical records, prevent inadvertently leaked or lost, is prohibited without the authorized personnel or other irrelevant personnel consult, patients copying the medical records, in order to avoid leaking the possibility of patient privacy, and increase the intensity of punishment for records reveal that behavior.

In the process of diagnosis, medical accident report, the hospital ward round of consultation and case discussion, and treatment of disease has no direct relation member without the consent of the patients can't attend, watching. Hospital arrange intern doctors and nurses, clinical practice, to be based on the principle of friendly consultation, familiar with the voluntary, first to explain the reasons and consent of the patients, patients with relevant legal agreement when necessary. Academic conferences, seminars and published papers, etc., to the patient's name or consent of the patients even sign relevant legal documents. At the same time, the medical institutions should also reform the existing administrative system and the state administrative department of health should also strengthen the management of hospital medical behavior and supervision, increase of medical institutions of administrative penalties of patients' right of privacy infringement. Medical institutions shall establish corresponding internal also supervision system, such as by telephone, letters, pays a return visit to in hospital diagnosis and treatment to the patients privacy protection of patients to investigate, to oversee the hospital medical personnel protection of patients right of privacy. Only from the administrative department of health and hospital internal administrative institutions at the same time, strengthen the medical and health care administration, to safeguard patient privacy is protected by a practical and effective.

\section{CONCLUSION}

Protect the patient's privacy and directly related to the vital interests of every person in the society. Patients' right of privacy is the patients have an inalienable human right, is the embodiment of the patients with dignity. Infringement of ignoring the consequences of patients' right of privacy sometimes, even cause irreparable damage. Health providers to protect patients right to privacy is not only the need of morality, is also the law shall perform the obligations, but also the need of medicine itself. Prescriptions without protective medical treatment, patients privacy infringement, may hurt patient dignity as human beings, may lead to various social problems.

\section{REFERENCES}

[1] Bian Li, Wang Xiaoli, Zhao Zhen. The Research on Co-authorship Network in Medical Information Education in China[A]. Proceedings of 
2nd International Conference on Social Science and Higher Education(ICSSHE 2016 V53)[C]. 2016

[2] Zhiyi Zuo. A few considerations to optimize the chance to get your research work published[A]

[3] Mindy Wang. Functional Activities \& Translational Medicine[A].

[4] Yajun Liu, Xinxi Xu, Fu Niu, Shulin Tan. Study on Overpressure Protection System of Air Contaminations for Mobile Medical Shelters[A]. Proceedings of 2014 2nd International Conference on Applied Mechanics, Materials, and Manufacturing(AMMM 2014)[C]. 2014
[5] Hongli Zhai, Yujia Zhang. On the Obligation to Supply Medical Documents in Medical Malpractice Litigations[A]. Proceedings of 2014 4th International Conference on Applied Social Science(ICASS 2014 V52)[C]. 2014

[6] Kadi Lubi, Triin Vihalemm, Pille Taba. Illness-related Information Seeking: The Case of Parkinson's Disease Patients[A]. Proceedings of 2014 2nd International Conference on Social Science and Health(ICSSH 2014 V59)[C]. 2014 